\title{
Queer de William S. Burroughs: Ser queer antes de la teoría queer'
}

\section{Queer by William S. Burroughs: Being queer before the queer theory}

\author{
JORGE ALOY \\ Universidad de Lomas de Zamora \\ Argentina \\ jorgealoy@yahoo.com.ar
}

(Recibido: I2-O6-20I5; aceptado: I8-I2-2OI5)

Resumen. Uno de los resultados que dejaron las luchas de las minorías sexuales estigmatizadas por el sida, a fines del siglo $X X$ en EE.UU., fue la resignificación del vocablo "queer". En consecuencia, esta situación generó teorizaciones académicas que permitieron hacer visibles ciertos dispositivos de poder. En el presente trabajo vamos a realizar un breve recorrido por algunos aspectos relacionados con el poder y la construcción social de la sexualidad. A partir de ello procuraremos señalar cómo es el tratamiento que se le da al término "queer" en la novela Queer (1985) de William S. Burroughs.

Palabras clave: queer; cuerpo; sexo; sexualidad; poder.
Abstract. One of the results left by the struggles from the USA sexual minorities stigmatized through AIDS, at the end of the twentieth century, was the new meaning of the word "queer". Accordingly, this situation generated an academic theorizing that made visible certain power devices. In the present work we are going to look at some aspects related to power, as well as at the social construction of sexuality. From this, we will attempt to point out which kind of treatment is given to the word "queer", in the novel Queer (1985) by William S. Burroughs.

Keywords: queer; body; sex; sexuality; power.

\footnotetext{
I Para citar este artículo: Aloy, Jorge (20I6). Queer de William S. Burroughs: Ser queer antes de la teoría queer. Álabe 14. [www. revistaalabe.com]

DOI: IO.I5645/Alabe2oi6.I4.I
} 


\section{Una palabra en tensión}

El término "queer" a lo largo del siglo XX sufrió diversos cambios en su significación. Mientras que a principios de esa centuria remitía a lo raro, a lo extraño y a la homosexualidad, a fines de la década del ochenta y comienzos de la del noventa, como consecuencia de las luchas contra el avance del VIH emprendidas en Nueva York por un grupo denominado Queer Nation, la expresión va a ser resignificada. Queer Nation, a la vez que advirtió la homofobia del poder político que dejaba crecer exponencialmente la cifra de muertos por sida, insistió, tal como señala Robert McKee Irwin (2OIO), “en rechazar las identidades binarias (hombre/mujer, hétero/homo, masculino/femenino, activo/pasivo, etc.) al plantear y asumir identidades más fluidas y más variadas” (p. 266). En consecuencia, este movimiento que cobijaba en sus filas a todo tipo de sexualidades marginadas se propuso cuestionar a las instituciones creadoras del discurso binario, mientras que simultáneamente interrogaba a los grupos gay por reproducir el discurso impartido desde los lugares de poder. McKee Irwin (2OIO) va a decir que los activistas del Queer Nation "retomaron el vocablo queer, apoderándose de lo que antes se había usado para agredirlos, y convirtiendo su significado en un calificativo positivo" (p. 266). Lo que se había producido era una especie de corriente que ejercía su fuerza hacía afuera, hacia el poder político y religioso que se hallaba en el centro de dominación, pero también hacia adentro, hacia el corazón mismo de los que luchaban desde el margen. De todos modos, si se habla de poder y discurso, Judith Butler (2002) descree de la posibilidad de que exista una renovación completa del vocablo, y se pregunta “ ¿Por qué debemos entender su fuerza convergente como un efecto acumulado del uso que limita y a la vez habilita su reelaboración?” (p. 35). Para Butler (2002) existe una relación entre el carácter performativo del discurso, en cuanto acto de habla, y el género. En ese sentido expresa que “(...) No se trata solamente de comprender cómo el discurso agravia a los cuerpos, sino de cómo ciertos agravios colocan a ciertos cuerpos en los límites de las ontologías accesibles, de los esquemas de inteligibilidad disponibles" (p. 3I5). Intentar comprender cómo aquellos que fueron marginados utilizan el discurso dominante tanto para criticarlo como para conseguir su propia reivindicación, permite a Butler coincidir con Michel Foucault en que es muy débil pensar que la sociedad reprime el sexo por economía.

Mucho más que un mecanismo negativo de exclusión o rechazo, se trata del alumbramiento de una red sutil de discursos, de saberes, de placeres, de poderes; no se trata de un movimiento que se obstinaría en rechazar el sexo salvaje hacia alguna región oscura e inaccesible, sino, por el contrario, de procesos que lo diseminan en la superficie de las cosas y los cuerpos, que lo excitan, lo manifiestan y lo hacen hablar, lo implantan en lo real y lo conminan a decir la verdad: toda una titilación visible de lo sexual que emana de la multiplicidad de discursos, de la obstinación de los poderes y de los juegos del saber con el placer. (Foucault, 2OI4: 72-73) 
Para Foucault, el efecto que la represión podría causar sería contrario al deseado: en vez de que la libertad sexual se contraiga, sucedería que se sentiría estimulada, alentada, con bríos para oponerse a la represión. Por lo tanto, el resultado que Foucault estaría pensando es que en las sociedades más reprimidas podrían surgir, de acuerdo a esta hipótesis, mayores libertades sexuales. Sin embargo hay algo en lo que Butler (2002) no acuerda, porque dice que Foucault no afronta los modos “en que opera la 'represión” como una modalidad del poder productivo" (p. 48). Lo cierto es que existe una irradiación multiplicadora de los discursos que se produce a través de ciertos procesos que tendrán influencias sobre los cuerpos, y que funciona, además, una serie de mecanismos que producen saber, y trabaja con la diseminación de estos discursos en el forjamiento de estrategias de poder. Por consiguiente, los discursos están estrechamente ligados a los dispositivos políticos. Butler (2002) no cree que "la materialidad de los cuerpos es sencilla y únicamente un efecto lingüístico que pueda reducirse a un conjunto de significantes. Tal distinción pasa por alto la materialidad del significante mismo" (p. 57). Por supuesto, hablar de la materialidad a través y a partir del lenguaje, como si éste desplegara sobre los cuerpos su carácter mimético o performativo, es darle al lenguaje un estatuto que no ostenta. El lenguaje no solo no remite miméticamente al objeto que nombra sino que, además, un enunciado no deviene realidad. Por lo tanto, el lenguaje no tiene carácter mimético ni tampoco puede crear realidad. Ahora bien, en este sentido el lenguaje no crea el cuerpo, solo lo enuncia. En suma, debemos pensar que en el entrecruzamiento del discurso y el poder se hallan los cuerpos. Una forma de ejercer poder es impartir directivas sobre el deseo del otro: en el momento en que el discurso imparte esa directiva se ponen en juego los dispositivos del poder. En el siglo XX, afirma Foucault (2OI4) que “estamos en una sociedad del 'sexo' o, mejor, de 'sexualidad': los mecanismos del poder se dirigen al cuerpo, a la vida, a lo que la hace proliferar, a lo que refuerza la especie, su vigor, su capacidad de dominar o su aptitud para ser utilizada" (p. I40).

En la actual sociedad del sexo, tal la denominación de Foucault, reconocemos a grandes rasgos dos formas de ver lo queer. Por ende, para revisar la novela Queer (I985) de William S. Burroughs, más allá de las posibilidades lingüísticas que encierre el término, debemos atender al momento histórico en que se utiliza.

Queer es una novela tardía en la bibliografía de Burroughs. Si bien se publicó en I985, fue escrita en I952. A pesar de los treinta y tres años que median entre la producción y la publicación no se encuentran cambios significativos en la connotación del vocablo. Burroughs, a través del narrador, pareciese que intenta una utilización del término en donde se le resta ironía, desprecio y cierta anomalía. No alcanza a ser ni el principio de una resignificación del vocablo ni la reivindicación de una identidad sexual, pero mínimamente se vislumbra -si eso es posible- alguna neutralidad en el uso. Llamativamente, la editorial Anagrama en la primera edición en español la publicó con el nombre Marica. Posteriormente, debido al interés académico que había suscitado la obra y con la intención editorial de acercarse a los estudios de la teoría queer, se publicó con el título en inglés. 
En la novela Queer nos encontramos con la acepción primera, pero ya incluye los matices que mencionamos. No debemos olvidar que, como dice McKee Irwin (2OIO), que "Lo queer entonces era lo anormal, lo diferente, lo perverso y por eso su pronunciación implicaba una repulsión” (p. 266). Los matices que introduce Burroughs quizá sean un condimento para lo que vendrá. Probablemente debamos recordar que en el mismo año de publicación de la novela, la muerte del actor Rock Hudson sirvió en EE.UU. para poner en evidencia que el sida estaba rondando el mundo y se lo intentaba ocultar debajo de la alfombra. Muy pocos años después, el grupo Queer Nation, entre otros, asumió la lucha contra la pandemia de esta enfermedad. Beatriz Preciado (2009), en relación a esta enfermedad dice que

El virus del sida, como si se tratara de una cristalización biopolítica tardía de algunas intenciones eugenésicas que Occidente había puesto a prueba a través del experimento nazi, cambia el medioambiente y las condiciones generales de inmunidad en el que se inventan nuevas estrategias de supervivencia y se llevan a cabo otras micropolíticas revolucionarias. (P. I63)

Lo que Preciado reafirma es que la enfermedad no vino a crear nuevas formas de represión sino que a corroborar las estrategias de poder que ya circulaban un siglo atrás. Este nuevo panorama es el que asumen los grupos activistas.

\section{En la novela}

Queer transita el camino de la experimentación. Lee, el protagonista, ofrece su cuerpo a cualquier ensayo: el alcohol, la marihuana, el sexo y, muy a pesar suyo, el amor no correspondido. Lee, un joven de Estados Unidos, se instala en la Ciudad de México que para él representa un cúmulo de extrañezas. Para varios escritores, México resultó, durante el siglo XX, una meca del exotismo casi en la misma medida que lo había sido América para los europeos en los momentos de la conquista. Además de Burroughs podemos mencionar a Malcolm Lowry, Ambroise Bierce, André Breton, Leonora Carrington, entre muchísimos artistas que se instalaron por algún tiempo o definitivamente en ese país. La búsqueda en común que llevaban los pintores y escritores que se establecían en México era el encuentro con el otro. Para el protagonista de Queer la Ciudad de México era aquel lugar donde la muerte coqueteaba con lo cotidiano, pero también era un lugar de libertades alcohólicas y sexuales en donde nadie se involucraba en juzgar lo que cada uno hacía con su existencia.

La vida de Lee parecía reducida a tres ambiciones: el encuentro con cuerpos de su mismo sexo, conseguir algún reconocimiento social y el hallazgo de ayahuasca. Cada una de estas ambiciones tenía una contracara. En el caso del deseo de las relaciones sexuales se escondía el deseo de amar. El anhelo por el reconocimiento social hacía que Lee se 
transforme en un personaje verborrágico que fabulaba insólitas historias: el síndrome de abstinencia de sustancias hacía que él necesite un público con quien lucirse. Por último, el encuentro de ayahuasca podría concretar las otras dos ambiciones de Lee.

En estas ambiciones será donde Lee ponga en juego su cuerpo para cada experimentación. Necesitaba a Allerton, un joven alto y desgarbado, pero éste negaba su propia sexualidad: “¿QQué quiere él de mí?’ No se le ocurría pensar que Lee era marica, pues asociaba la homosexualidad con por lo menos cierto grado de afeminamiento declarado" (Burroughs, 2OI2: 42). Lee consiguió que Allerton finalmente lo acompañe en un viaje por América para buscar la ayahuasca. Las dudas que Allerton tenía para aceptar el viaje se relaciona con lo que sostiene Barbara Smith (2005) en El eje del mal es heterosexual: “(...) Las personas se sienten generalmente amenazadas sobre cuestiones de sexualidad, y para algunas la mera existencia de homosexuales pone en cuestión su sexualidad/heterosexualidad" (p. 63). Allerton para poder reconocer su homosexualidad aceptó viajar con Lee, ya que el viaje significaba salir de sus lugares habituales y alejarse de la gente que conocía. Beatriz Preciado (2009) en "Terror anal” plantea la posibilidad de una castración anal como certificación de la heterosexualidad: "En el hombre heterosexual, el ano, entendido únicamente como orificio excretor, no es un órgano. Es la cicatriz que deja en el cuerpo la castración. El ano cerrado es el precio que el cuerpo paga al régimen heterosexual por el privilegio de su masculinidad” (pp. I36-7). En esta castración está asentada la hegemonía heterosexual que se instaló naturalmente en las sociedades. De este modo, los cuerpos están inscritos en una realidad histórica que tiene relación con los dispositivos de poder. La exclusión que ejerce le heterosexualidad dominante está planificada, de acuerdo a como lo piensa Beatriz Preciado, a partir de los cuerpos con anos cerrados hacia los cuerpos con anos abiertos, por ese motivo sostiene que "El ano castrado es el armario del heterosexual" (2009: I37).

El viaje de Lee con Allerton, en definitiva, comenzó: Ciudad de Panamá, Quito, Manta, Guayaquil, Salinas, Ambato y Puyo. Lee era el que tenía dinero, y conseguía ejercer cierto poder sobre Allerton: le había ofrecido un contrato económico para que viaje con él a cambio de que mantengan relaciones dos veces por semana. Mientras Lee necesitaba amar, Allerton solo realizaba un intercambio comercial. Lee amaba con pasión y estaba motivado por la búsqueda de ayahuasca o yage. Para pensar en la relación entre pasión, sexo y adicción Anthony Giddes (i995) señala que

El amor apasionado fue originariamente una entre otras pasiones; su interpretación estaba muy influida por la religión. La mayor parte de las disposiciones emocionales pueden ser pasiones, pero en la sociedad moderna la pasión se ve reducida al reino del sexo y una vez así queda más y más ensordecida en su expresión. La pasión se admite hoy solo con renuencia y reservas, incluso en lo que concierne a la misma conducta sexual, en parte porque su papel como "fuerza compulsiva" se ha visto sustituido por la adicción. (P. I82) 
Allerton, si bien se mantenía al margen de la pasión de Lee, cumplía con el contrato. De alguna u otra manera, aunque por un límite de tiempo pautado, su cuerpo estaba a disposición de Lee. Los lugares que recorrían distaban mucho de poseer sociedades modernas como sí podrían hallarse en EE.UU., pero Lee que estaba acostumbrado a que en su país lo persigan por tener droga encima o que lo miren de reojo por homosexual, encontraba ahora espacios de libertad para el sexo y la pasión. "No hay espacio para la pasión en los esquemas rutinarios que nos proporcionan seguridad en la vida social moderna." (Giddens, I995: I82). Lee había escapado de la rutina, y le llamaba la atención no el exotismo ni la precariedad de los pueblos, sino la libertad de los cuerpos para ofrecerse a los placeres sexuales, como si no existiera la represión sexual o, por el contrario, como si la represión estimulara la libertad sexual, tal como hipotetiza Foucault (20I4).

Cuando la búsqueda de la ayahuasca se hizo infructuosa, emprendieron el viaje de vuelta. Lee comprendió que el fracaso por no haber encontrado la planta implicaba el retorno a México y, en consecuencia, la pérdida de Allerton. Consecuentemente, el regreso de Lee no lo alejaba solo de las posibilidades sexuales sino también de la pasión.

\section{Penúltimas palabras}

De la novela Queer de William S. Burroughs debemos rescatar un mundo en donde las restricciones y las represiones se cumplen con gran verosimilitud respecto del mundo del siglo XX, pero con una salvedad: la circulación de la homosexualidad se presenta como un elemento contracíclico en la construcción ficcional. En otras palabras, en un mundo dominantemente heterosexual, el homosexual no aparece caricaturizado, a pesar de ser la contracara del mundo binario. Notamos que la atmósfera de la novela y la homosexualidad de los personajes ofrecen una respuesta a la construcción social de la sexualidad. Por supuesto, en los términos en que la teoría hoy se conoce, podemos afirmar que Lee no es un queer avant la lettre, pero tampoco encuadra en la definición de principios de siglo. Lee ni siquiera era afeminado, y por mucho tiempo eso había implicado un rasgo o una marca indeleble en el cuerpo. Como sostiene Bárbara Smith (2005): "A diferencia de muchos otros grupos oprimidos, los homosexuales no constituyen un grupo cuya identidad esté definida por nacimiento" (p. 63). Esto representa para el poder una dificultad histórica que se hace manifiesta en la transmisión de los discursos que apuntan a disciplinar y regular la sexualidad, ya que durante mucho tiempo se utilizó la apariencia heterosexual para pasar desapercibido. La violencia de los discursos esconde en su regulación el temor a ser excluido. De ahí que Lee utilice el recurso de no mostrar rasgos externos de su sexualidad.

En el centro de la novela está el deseo. El deseo es una construcción cultural tallada desde los ornamentos del poder que, a través de sus discursos, alienta la subordinación al deseo heterosexual. Preciado (2009) pone las cosas en su lugar cuando dice que "No hay deseo homosexual y deseo heterosexual, del mismo modo que tampoco hay deseo 
bisexual: el deseo es siempre un recorte arbitrario en un flujo ininterrumpido y polívoco" (p. I64). Lee enfrenta esta distinción y se transforma en un personaje de transición en lo queer.

Por último, en la praxis, cuando en la década de los noventa en EE.UU. el vocablo "queer" cambió de dueño, no significó un avance lingǘstico sino un trofeo de guerra. La palabra había sido usurpada al poder. El queer rechazó los eufemismos que lo nombraban y se reconoció con el lenguaje dominante. De ese modo lo vació de contenido. 


\section{Referencias bibliográficas}

- Burroughs, W. S. (20I2). Queer. Buenos Aires: Editorial La Página S. A.

- Butler, J. (2002). Cuerpos que importan. Buenos Aires: Paidós.

- Foucault, M. (20I4). Historia de la sexualidad, I. La voluntad de saber. México: Siglo Veintiuno.

- Giddens, A. (I995). La transformación de la intimidad. Sexualidad, amory erotismo en las sociedades modernas. Madrid: Cátedra.

- McKee Irwin, R. (20I0). Teoría queer. En Szurmuk, M. y McKee Irwin, R. (Coord.) Diccionario de estudios culturales latinoamericanos (pp. 266-270). México: Siglo XXI EditoresInstituto Mora.

- Preciado, Beatriz (2009). Terror anal: apuntes sobre los primeros días de la revolución sexual (Epílogo). En Hocquenghem, Guy. El deseo homosexual (pp. I33-I74). Barcelona: Editorial Melusina.

- Smith, Barbara (2005). Homofobia, ¿por qué hablar de ello? En Romero Bachiller C., García Dauder S. y Bargueiras Martínez C. (Eds.). El eje del mal es heterosexual. Figuraciones, movimientos y prácticas feministas queer (pp. 6I-65). Madrid: Traficante de sueños. 